\title{
Um Episódio para a História do Serviço Público
}

OTACIANO DA COSTA NOGUEIRA FILHO

O Estatuto dos Funcionários Públicos poderia ser uma conquista de mais de cinqüenta anos de nossa legislação se o Congresso Nacional tivesse aprovado o primeiro projeto apresentado com esse objetivo pelo deputado Moniz Sodré, em novembro de 1913.

O fato é pouco referido, mas nem por isso deixa de ter inestimável interesse para a história do serviço público no Brasil. A proposta do parlamentar baiano revela não só o padrão intelectual da representação popular da época, mas sobretudo a importância da participação do legislativo, na busca de soluçőes para os problemas administrativos mais relevantes.

Este artigo, ao lado de seu interesse meramente informativo, pretende ser uma homenagem ao autor do projeto, que, embora frustrado em seus objetivos, não perdeu a dimensão histórica das iniciativas pioneiras.

\section{O ESTATUTO NOS PAISES} EUROPEUS

Quando o deputado Moniz Sodré apresentou o seu projeto à Câmara, Alemanha e Itália já tinham promulgado seus estatutos dos funcionários: a primeira em 1873 e a segunda em 1908. França e Bélgica estavam em vias de fazê-lo. A Inglaterra (como os Estados Unidos) há muito tinha caracterizado a situação jurídica de seus servidores públicos, ainda que por outra via. A proposição do deputado baiano, portanto, nem era precipitada, pois o assunto vinha sendo discutido - pelo menos na Câmara francesa desde 1844 , nem chegava tarde para um país de história reflexa, como era o Brasil.

Na Bélgica, o primeiro projeto é o do deputado Bergé, apresentado em 1903. Do mesmo ano é a tentativa feita na Itália pelo senador Zanardelli, em 6 de junho. $O$ projeto francês, do deputado Buisson, é de 1908. A defasagem, com relação ao nosso $P$ ais era, pois, de cerca de dez anos.

Foi, porém, Aristide Briand, onze vezes Primeiro-Ministro francês, que fez do Estatuto ponto básico de seu programa de governo. Justificou a medida no discurso de apresentação de sua plataforma reformista, pronunciado em Saint-Chamond, a 10 de abril de 1910 , dizendo: "só assim os funcionários se livrarão da influência dos políticos e 
estes, por sua vez, ficarão livres dos pedidos dos funcionários". 1 Em 30 de junho formalizou a apresentação do projeto perante a assembléia. Teórico do sindicalismo revolucionário, preconizou para o problema funcional uma solução conservadora, o que lhe valeu, desde logo, a oposição de alguns de seus companheiros. Com o episódio, contribuiu para confirmar a procedência do aforismo segundo o qual "não há ninguém mais conservador do que um revolucionário no poder".

No fundo, a intenção de Briand, como chefe supremo da administração, devia ser a de institucionalizar em seu pais a fórmula inglesa de separação entre a política e a administração, graças à qual "não somente a influência política quase que deixou de agir sobre as nomeações, como desaparemoçõ, pode-se dizer, em matéria de pro-

$\mathrm{Na}$ verdade, a luta pelo Estatuto não tinha começado com ele. Nem vinha deste século; procedia do anterior. Originou-se da pena dos publicistas e daí ganhou a tribuna parlamentar. Só depois - lá como aqui - sensibilizou a administração, para se transformar em programa de governo.

Nos paises europeus, portanto, o Estatuto foi uma imposição das profundas transformações políticas e econômicas por que passaram o Estado e a Sociedade. As velhas doutrinas do precarium ou do "aluguel de coisa certa" - reminiscência romana a primeira, e feudal a segunda - já não atendiam, em meados do século, às crescentes necessidades da centralização administrativa. A ampliação dos estudos de direito público, por sua vez, também contribuiu muito para o advento das novas concepçöes liberais sobre a natureza dos cargos públicos. De tal sorte que, no início do século $X X$, o Estatuto era uma idéia vitoriosa na maioria dos países europeus.

\section{A ADMINISTRAÇÃO NA AMÉRICA}

A administração colonial, tanto na América espanhola como na América portuguesa, padeceu de todos os vícios típicos das respectivas administrações metropolitanas. Dois deles foram excessivamente perniciosos. A praxe do aluguel ou arrendamento dos cargos públicos - especialmente daqueles relacionados com a fiscalização e a arrecadação dos tributos da coroa - e a alternação entre as políticas de excessiva centralização e de exagerada descentralização da autoridade. A descentralização quase sempre gerou os conflitos entre a autoridade civil $e$ a eclesiástica; a centralização generalizou os abusos.

$\mathrm{Na}$ América inglesa, a colônia se beneficiou da doutrina da metrópole, onde os funcionários eram considerados "como tendo o direito de ficarem em posse pacífica de seus lugares, tanto tempo quanto desempenha-

1. Aristide Briand, politico francês, nascel em Nastes, em 1862 e faleceu em Paris, em 1932. Advo foi, durante ado e depois depulado do sindicalismo revolucionário. Onze vezes presidentado Conselho, dirigiu o governo francess no de damente durante a Grande Guerra, de 29717. outubro de 1915 a 17 de março de acorComo ministro do exterior assinou os $R \theta^{-}$ dos de Locarno (16 de outubro de 1925) Cont. cebeu o prêmio Nobel da Paz de 1926. des LOUSSE, et LAUNAY, J. de Dictionnaire jours. grandes contemporain's da 1776 à nos

Lausanne, Editions Rencontre, 1969. I'Angleler-

2. LOWELL. Le Gouvernement de l'Anglelo, re. Trad. francesa de Nerinck, Paris,

Tomo I, p. 207. 
rem convenientemente suas funções". ${ }^{3}$ Além disso, graças à relativa autonomia da administração local, prevaleceu o sistema de eleições, pelo menos para os cargos públicos mais importantes. Nem por isso, no entanto, foi menos corrupta a administração depois da independência. O que hoje parece fora de dúvida é que, se esse método não criou, pelo menos favoreceu a convicção de que os eleitos eram proprietários dos cargos. E foi essa crença, inegavelmente, que conduziu à implantação do spoil system, introduzido no início da administração Jackson, em 1829.

Sintetizado na frase célebre do senador Marcy - "to the victors belongs the spoil" - o sistema durou praticamente até 1883 , quando foi revogado pelo famoso Pendleton Act, de 19 de janeiro. Os seus efeitos foram tão devastadores e comprometeram de tal modo o serviço público civil nos Estados Unidos que o relatório de uma investigação determinada pelo Congresso em 1866 chegava a afirmar que "havia tantos iadrões no serviço público que a honestidade era a exceção". 4

A solução encontrada pelo governo americano para o problema funcional, no entanto, não fol a do Estatuto. A lei de 19 de janeiro de 1883 garantia aos funcionários de determinadas áreas administrativas, não só a seleção por concurso, mas sobretudo a estabilidade que os protegia das conseqüências do spoil. $\mathrm{Na}$ prática, porém, os resultados foram os mesmos que os obtidos onde se adotou o Estatuto.

\section{O SERVIÇO PÚBLICO BRASILEIRO} NO IMPÉRIO E NA REPÜBLICA

O caso particular do Brasil não é muito diferente da situação geral do Continente, no século XIX. Depois da independência, herdamos o aparelho administrativo da corte que em 1821 aqui deixou el-Rei. E, com ele, os vícios e os problemas da enorme burocracia da época. Basta assinalar que os Regimentos, as Cartas de Lei, os Alvarás e as Ordenações, típicas do período colonial, foram a nossa legislação ordinária, durante muitos anos depois da Constituição de 1824. As veIhas Ordenações Filipinas, por exemplo - velhas de 1603 -, persistiram integralmente até 1824 e, a partir de então, nos regeram parcialmente até 1917, quando entrou em vigor o Código Civil Brasileiro.

A legislação, na verdade, pouco revela do aparelho administrativo do Estado entre nós, porque a distonia entre a lei e a realidade, no Brasil, como ensina José Honório Rodrigues, ${ }^{5}$ é muito mais antiga do que usualmente se acredita. Exemplo típico, segundo o grande historiador, é o que se encontra na carta de Mem de Sá ao Rei, de 31 de março de 1560: "Esta terra não se deve nem pode regular pelas leis e estilos do Reino; se vossa alte-

3. O princípio está inscrito no art. III, seçăo 1.a da Constituiçăo dos Estados Unidos, relativamente aos juizes, que "manterăo seus relativamente aos juizes, que "manteră (shall hold their offices during good behavior), aplicando-se, por extensăo, aos funcionários permanentes da Uniăo.

4. Cf. LEFAS. L'Etat et ses fonctionnaires. Paris, 1913, p. 76.

5. Teoria da História do Brasil. SP, Cia. Editora Nacional, $3 .^{a}$ rev. e atualizada, 1969. Coleçăo Brasilliana, formato grande, vol. 11, p. 158 . 
za não for muito fácil em perdoar não terá gente no Brasil". ${ }^{6}$

Assim é que, embora não encontre amparo em nenhum texto legal, pois decorriam só do poder de arbítrio, as "derrubadas gerais" tornaram-se a mais poderosa $\theta$ inamovivel das instituições de nosso serviço público, ao longo de todo o periodo colonial. A "derrubada" era uma versão atenuada do "espólio". A cada sucessão partidária no poder substituia-se praticamente todo o corpo funcional. A historiografia e a literatura brasileiras estão cheias de referências à prática.

$\mathrm{Na}$ República, o sistema ampliou-se ainda mais. Os atingidos não eram somente os funcionários e os agentes do executivo. Sob o nome expressivo de "degola", aplicava-se a "derrubada" também ao legislativo, ao qual cabia, pelo instituto do "reconhecimento" ou da "verificação de poderes", a fabricação das maiorias governamentais, penosamente construídas a "bico de
pena".

Não é difícil calcular o que a "derrubada" significava para a continuidade administrativa dos programas governamentais. Porque, se a "degola" era um problema institucional e fundamentalmente político, a "derrubada" dizia intimamente com a produtividade do serviço público, sobre constituir uma questão de nítidas implicações
sociais.

A política de pessoal se resumia naquilo que o deputado Moniz Sodré chamou de "regime de injustas nomeações, acintosas demissões e irritantes preterições". 7 o quadro da rotatividade funcional está nitidamente traçado no discurso do autor do pri- meiro projeto de Estatuto: "Quando essa chusma de indivíduos, que são nomeados por favor, e por isso geralmente incompetentes, começam a adquirir as habilitações necessárias com a prática obtida no exercício diário das suas funções, são substituídos por outra chusma de ineptos que só se recomendam pela proteção com que săo favorecidos, e que não tardarão a ter a mesma sorte dos seus antecessores, quando se forem afeiçoando ao ofício, perdendo os respectivos lugares, a fim de ser acomodada e satisfeita a avalanche dos novos protegidos. Daí a perpetuação da incapacidade na administração do Estado." 8

A linguagem cáustica da eloqueência parlamentar não desfigura nem agrava as implicações de um problema que era sabidamente sério. Especialmente as de ordem econômica, como se verá em seguida.

\section{O CUSTO DAS "DERRUBADAS"}

Na sessão da Câmara de 8 de novembro de 1913 entrou em discussão - projeto 118 , de 1913 , "autorizando - presidente da República a abrir, pelo Ministério da Fazenda, um crédito extraordinário de 40:758 $\$ 500$ para ocorrer ao pagamento a Pedro Rodrigues de Carvalho, em virtude de sentença judiciária". A intervençăo do deputado Maurício de Lacerda esclarece como as proposições dessa natureza se relacionavam com as "derrubadas":

6. Idem, ibidem.

7. Cf. justificativa do projeto, "in Annaes da Camara dos Deputados; Sessóes de ${ }_{1915}$ 18 de novembdo de 1913; RJ, Imp. Nac., vol. IX, p. 251.

8. Discurso na sessão de 6 de novembro de 1913, Anais cit. p. 241. 
Este projeto é mais um dos frutos das derrubadas. O funcionário de que ele trata foi demitido por desídia, conforme alegou o Ministro da Fazenda de então, no juizo singular onde se intentara o feito. Tendo intentado ação judiciária na $2^{\mathrm{a}}$ Vara, ai perdeu o mesmo funcionário, vendo-a julgar improcedente; apelando, porém, o autor, para o Supremo Tribunal, este deu provimento para reformar a sentença apelada, só porque o processo de demissão fora irregular, não se podendo assim apurar a procedência da culpa que motivara a mesma demissão. Por força desse acórdão, que é uma lide em que foram esgotados todos os recursos judiciários pela Fazenda Nacional, vai o funcionário referido ser integrado percebendo os vencimentos que deixou de receber pelo tempo em que esteve afastado do cargo. 9

Esta situação tornou-se corriqueira, desde o início da República. Transformou-se quase uma rotina. Reintegrado - funcionário vítima da derrubada, arcava o Tesouru com ônus duplo, como esclarece o Deputado Maurício de Lacerda:

De sorte que pela sentença a cumprir se dará a sua reintegração no quadro onde já existe outro em seu lugar (que) irá receber os vencimentos do tempo em que esteve dele afastado, isto na importância do crédito pedido no projeto $(40: 758 \$ 500)$ os quais já foram igualmente recebidos pelo atual funcionário, e, outra anomalia, ainda, passarão a figurar no quadro dois funcionários em um mesmo lugar, havendo este ano o governo pedido já, em mensagem ao congresso, um crédito extraordinário, visto como o da dotação orçamentária havia já sido pago ao primeiro, para pagar esse outro segundo escriturário, que deverá ser reintegrado em obediência à sentença que assim determinou. E, como o outro funcionário não pode ser demitido sem que para isso dê motivo, e se for por esse, de que não tem a menor culpa, será vitorioso em qualquer ação judiciária que tente em seu favor, segue-se que vão continuar ambos como funcionários em duplicata, também assim pagos e depois aposentados pelo Estado." 10

Assumia tal gravidade a repetição desses fatos, que o deputado Josino Araújo, alarmado com os dados do Tribunal de Contas, segundo os quais "as condenações da União, em virtude de sentenças judiciárias por lesões de direitos individuais, já montavam a mais de 50 mil contos" (em cerca de vinte anos), apresentou emenda a um projeto de abertura de crédito, determinando:

Sempre que a União for condenada, por sentença judiciária, a pagamentos resultantes de lesões de direitos individuais, o Ministro da Fazenda, na mesma ocasião em que ordenar o pagamento, enviará à autoridade competente os papéis respectivos, a fim de ser proposta pelo representante da Fazenda Nacional ação regressiva

9. Discurso na sessão de 8 de novembro de 1913. Anais cit. p. 427 e 428 .

10. Idem, Ibidem. 
contra a autoridade que der causa à condenação. 11

Para que se tenha idéia do que representava a cifra coligida pelo Tribunal de Contas, basta citar o fato de que o Orçamento do Ministério da Guerra, no exercício de 1913 , era de cerca de 73 mil contos!

\section{PROBLEMA INSTITUCIONAL E O AFA REFORMISTA}

Os problemas administrativos da $\mathrm{Re}$ pública, à época, não se cingem, porém, à instabilidade dos quadros humanos. A inexistência de uma lei geral, como o pretendido Estatuto, fazia depender do legislativo as providênclas mais rotineiras, relacionadas com o funcionalismo da União. Em dez dias do mês de novembro de 1913, apareceram na ordem do dia da Câmara projetos de lei relativos aos seguintes problemas típicos; concessão de licença sem vencimentos, a diversos funcionários, inclusive um trabalhador braçal da EFCB; cancelamento de faltas ao serviço e anulação de puniçōes; concessão de abono e aposentadorias; pagamento do prêmios a servidores contemplados, sem contar inúmeras aberturas de crédito, decorrentes de sentenças judiciárias. A amplitude que adquirira a administração já não comportava mais tais medidas. As condições vigentes em 1913 exigiam iniciativas mais condizentes com a modernização e o desenvolvimento do País.

Por isso mesmo, notava-se uma reformulação completa do direito substantivo no Brasil. O Código Clvil (que seria promulgado em 1916 e entraria em vigor em 1917) encontrava-se na fase final de sua longa tramitação legislativa. O projeto do Código Comer- cial de Inglês de Sousa pendia de pronunciamento do Senado, aprovado que fora pela Câmara, situação em que também se encontrava o projeto de organização da Justiça Militar. Dois anos antes, em 1911, Clóvis Bevilacqua, no auge de sua atividade criadora, tinha entregue ao Ministro da Marinha o anteprojeto do Código Penal Militar, submetido na época a uma Comissão Especial da Câmara, em virtude da revolta da esquadra em 1910. O ensino médio e o superior tinham sido objeto de uma reforma polêmica e muito combatida. Em discurso na Câmara, Augusto de Lima preconizava a elaboração de um Código Florestal. O mesmo fizera Dunschee de Abranches, relativamente ao Código de Contabilidade Pública, levando o assunto para a imprensa, onde foi longamente debatido.

É natural que, nesse ambiente reformista, também o sério problema do funcionalismo público fosse discutido. Coube ao deputado Moniz Sodré, representante da Bahia, levantar a importante questão na Câmara.

\section{O AUTOR E O PROJETO}

O Deputado Moniz Sodré tinha sido eleito em 1910, pelo 4 ? distrito da Bahia, representando a facção situacionista do Partido Republicano Conservador. Pouco antes de eleito pela primeira vez (foi reeleito em 1915), publicou em Salvador a obra As três escolas penais (1907). Nascido em 13 de junho de 1881, formou-se em ciências jurídicas e sociais pela Faculdade de Direito da Bahia, aos 23 anos de idade. Um ano depois de bacharelarse conquistou o cargo de professor

11. Loc. cit., p. 393-394. 
de direito penal da mesma Faculdade. Foi deputado estadual nas legislaturas de 1909-1910 e de 1911-1912, quando exerceu a liderança de seu partido. $\mathrm{Na}$ Câmara Federal tomou parte na comissão especial que estudou o Código Penal Militar, tendo integrado também a Comissão de Finanças, à época a mais importante do legislativo.

Especialista em direito e versado em assuntos financeiros e administrativos, estava em condições de se sensibilizar com a situação jurídica dos funcionários, assunto que, como demonstra a justificativa de seu projeto, estudou com notável erudição.

O projeto foi apresentado na sessão de 6 de novembro de 1913, precedido de longo e fundamentado discurso, em que 0 autor resumiu a argumentação desenvolvida na justificação do projeto. Seguindo a praxe regimental que vinha do Império, o presidente submeteu-o, no dia imediato, à apreciação do plenário, para que este o julgasse ou não objeto de deliberação. Era uma espécie de turno preliminar de votacão, no qual se resolvia se as proposições deviam ou não ter curso normal. Embora na República esse costume tivesse se tornado apenas uma formalidade, a apreciação preliminar era uma espécie de exame político de largo alcance. Durante o Império, serviu para economizar tempo e poupar esforços inúteis ao Legislativo, pois era através dessa votação que se impedia que os projetos tidos como inconvenientes, politicamente, tivessem tramitação regimental. Fol o que ocorreu, por exemplo, com as propostas de emancipação dos escravos, apresentada com notável tenacidade, por
Silva Guimarães, nas sessões legislativas de 1850,1851 e 1852 e que jamais lograram sequer entrar em discussão.

$\mathrm{Na}$ mesma sessão em que foi julgado objeto de deliberação o projeto, designou o Presidente os membros da comissão especial que deviam dar-lhe parecer: o autor, Deputado Moniz Sodré, e seus colegas, Felisbello Freire, Gastão Stockler, Pereira Braga e Carlos Maximiliano.

\section{A ATUALIDADE DO PROJETO}

Pela leitura do texto do Estatuto pretendido, que adiante se reproduz, notar-se-á, em confronto com a Lei 1.711 , de 28 de outubro de 1952, a atualidade do projeto. Entre outros principios, estão consagrados em seus dispositivos: a implantação do sistema do mérito, como forma de provimento inicial nos cargos públicos; estágio probatório; primeiro provimento obrigatoriamente na classe inicial; alternação das promoções por merecimento e por antiguidade; interstício para acesso; ajuda de custo de viagem, no caso de transferência; aposentadoria proporcional ou integral para os acidentados em serviço e gradação das penalidades.

A justificativa do projeto, longa e minuciosa, analisa exaustivamente todas as questőes concernentes à doutrina administrativa da época.

Assim é que, referindo-se por exemplo às correntes ideológicas que preconizavam soluçōes radicais para o problema funcional, alude o autor à posição do economista italiano Molinari, que pleiteava "reduzir o número das funções de nomeação do governo, confiando a empresas privadas a maior 
parte possivel dos serviços públicos". Mostrando, com base em outros tratadistas, que a adoção desse critério seria em si mesma contrária à própria essência do estado democrático, Moniz Sodré confessa-se partidário da intervenção do Estado, frisando: "Somos dos que pensam que o Estado, em vez de procurar restringir sempre a sua ação, deve, ao contrário, por um princípio de solidariedade humana, estendê-la em certos casos, ao domínio econômico e social, a fim de meIhor poder velar pela integridade de todos os direitos individuais e coletivos e promover o progresso geral e a felicidado pública. Sendo assim, como admitirmos vá ele alienar prerrogativas que the são intrínsecas e essenciais e constituem as principais razöes de sua própria existência?"

Só este tópico serve para mostrar como às vezes são mal rotuladas ou falsas as posições que passam à história como definitivas. Nem todos os liberais foram tão liberais e nem os conservadores tão conservadores como em geral se crê.

\section{CAPÍTULO I}

\section{PROJETO}

\section{Disposições Gerais}

Art. 19 Considera-se funcionário público, para os efeitos da presente lei, todo aquele que ocupa, no quadro normal da administração pública, um emprego permanente, sujeito à hierar-
quia e à disciplina.

Parágrafo único. Não se aplicam as disposições desta lei:

19 - aos militares de terra e mar;

2 - aos membros da magistratura e do magistério;
3 ? - aos membros do corpo diplomático e agentes consulares.

Art. 20 Dentro do prazo de três meses, a contar da data da promulgação desta lel, o Governo baixará os regulamentos da admiristração pública, organizando os diferentes corpos de funcionários e demais disposições necessárias à fiel execução dos preceitos e regras aqui estabelecidos.

\section{CAPITULOO II}

\section{Nomeações e Acessos}

Art. 3 Compete privativamente ao Poder Executivo prover os cargos públicos federais, salvas as restriçōes expressas na Constituição.

Art. 4ํ Para alguém ser admitido no quadro regular dos funcionários da administração pública, por via de primeira nomeação, é preciso dar provas da sua capacidade inicial necessária.

$\S 10$ Esta capacidade inicial do candidato se prova:

19 - por um concurso de admissão;

2 o - por um estágio probatório, seguido de um exame prático.

§ 2 : Uma indenização, que não poderá exceder de dois terços dos vencimentos fixados para o titular efetivo do argo, será concedida ao estagiário.

Art. 5ํ A primeira nomeação só poderá ser feita para o cargo menos elevado de cada categoria de funçöes.

Art. 6? Nenhum funcionário poderá ter acesso para o cargo superior se o seu nome não figurar no quadro de promoção e ele não tiver dois anos de serviço no cargo que ocupa. 
Art. 79 Os quadros de promoção serão organizados tendo-se em vista a antiguidade do funcionário ou o seu merecimento.

Art. 8? Os acessos para os cargos de superior categoria se fazem na razão de metade por antiguidade, metade por merecimento; nos outros casos a promoção se dá na razão de dois terços por antiguidade.

Art. 9? Os regulamentos da administração determinarão, para cada espécie de serviço, quais os cargos, para os efeitos da promoção, reputados de superior categoria.

Art. 10. O acesso ao grau mais elevado de cada serviço faz-se independentemente do quadro de promoção, mas a escolha não pode recair senão sobre um funcionário de categoria imediatamente inferior.

\section{CAPITULO III}

\section{Permutas, Remoções e Disponibilidade}

Art. 11. Os casos de permuta serão regulados pelos respectivos regulamentos; fora dos casos previstos e condições neles estipuladas, é nula qualquer permuta, de pleno direito.

Parágrafo único. Em caso algum será permitida a permuta que traga um prejuizo ao direito de promoção de qualquer outro funcionário.

Art. 12. Nenhum funcionário será removido, a não ser por medida disciPlinar, por pedido, por modificação operada nos quadros ou por necessidade de serviço, devidamente verificada.

Parágrafo único. Nestes dois últimos casos, as custas da viagem serão pagas pelo Estado, no lugar de onde - funcionário foi removido.
Art. 13. Um funcionário somente poderá ser posto em disponibilidade ou por pedido ou em caso de supressão do emprego.

Parágrafo único. O funcionário que foi posto em disponibilidade a pedido não tem direito a vencimento algum; no outro caso continuará a perceber integralmente os seus vencimentos.

\section{CAPITULO IV}

\section{Licenças e Aposentadorias}

Art. 14. Aos funcionários poderá ser concedida licença até o prazo mái'mo de dois anos.

$\S 1$ As licenças por mais de seis meses serão sempre concedldas com uma perda de um terço dos vencimentos.

$\S 2$ ? As licenças por mais de um ano serão sempre sem vencimentos.

Art. 15. O funcionário que se invalidar no serviço da Nação será aposentado com as seguintes vantagens:

19 - se contar menos de 30 anos de serviço, com vencimentos proporcionais ao tempo;

2 ? - se contar mais de 30 anos, com vencimentos integrais.

Art. 16. O funcionário que se inutilizar em ato de serviço ou por desastre ou acidente, ocorrido no desempenho das funçőes do seu cargo, será aposentado, com todos os vencimentos, qualquer que seja o tempo de serviço.

\section{CAPITULO $V$}

\section{Conselhos de Administraçãc}

Art. 17. Junto a cada Ministério funcionará um Conselho de Adminisda classe dos funcionários profissio- 
nais de mais elevada categoria, tendo preferência os mais antigos; outros três membros serão eleitos pelos seus colegas, de modo se dê a representação eqüitativa de todas as classes: - presidente será nomeado pelo respectivo Ministro.

$\S 2$ Estes conselhos exercem as atribuições que thes são conferidas pela presente lei e thes forem dadas pelos regulamentos orgânicos.

$\S 3$ A estes conselhos compete:

19 - organizar anualmente o quadro de promoção dos respectivos fun-
cionários;

2 - - resolver sobre as reclamações, no prazo de 15 dias, que, dentro de 40 dias, a contar da publicação do respectivo quadro, podem ser feitas pelos interessados;

3 ? - julgar, em última instância, após recurso dos interessados, nos processos administrativos para a aplicação das penas disciplinares dos nị 2,3 e 4 do art. 26 .

$4^{\circ}$ - julgar, em primeira instância, com recurso para o Conselho Superior de Disciplina, os processos para a aplicação das penas de nọs 5 e 6 do
referido art. 26;

5 ! - emitir opiniōes sobre todas as questões que interessem o pessoal ou - funcionamento do serviço público.

Art. 18. Estes conselhos se reúnem periodicamente em épocas determinadas; o Ministro poderá convocálo extraordinariamente, em casos de

Art. 19. Ao fim de cada ano o presidente apresentará ao respectivo Ministro um relatório a respeito dos tra- balhos do conselho, o qual deverá ser publicado no Diário Oficial.

\section{CAPITULO VI}

\section{Conselho Superior de Disciplina}

Art. 20. Haverá um Conselho Superior de Disciplina, composto de dois membros do Supremo Tribunal, escoIhidos por seus pares; dois membros do Tribunal de Contas, também eleitos por seus colegas; dois juizes federais, com sede nesta Capital, indicado um pelo Presidente do Supremo Tribunal Federal, e o outro pelo Presidente do Tribunal de Contas, e três funcionários, chefes de serviço, escolhidos por sorteio.

Art. 21. O presidente será o mais velho dentre os dois membros oriundos do Supremo Tribunal.

Art. 23.12 O sorteio dos três membros representantes dos funcionários será feito pelo presidente do Conselho, dois meses antes de terminar 0 mandato dos que estão em exercicio.

Art. 24. O mandato dos membros, quer do Conselho de Administraçăo, quer do Conselho de Disciplina, durará dois anos, e, em caso de falta, a substituição será feita pelo prazo necessário a completar este periodo.

$\S 19$ No momento de sortearem-se os três membros representantes dos funcionários, seis outros deverăo também ser sorteados para suplentes.

§ 2 : Quando a falta ou impedimento for dos outros membros do ConseIho, o Tribunal Federal ou o de Con-

12. Falta no original o art. 22. Trata-se de evidente engano de numeraçăo, apenas, repetido duas vezes nos Anals. 
tas, conforme o caso, logo indicará o substituto.

Art. 25. Compete ao Conselho Superior de Disciplina:

19 - julgar definitivamente os recursos relativos aos quadros de promoção;

$20^{\circ}$ - julgar, também em última instância, todos os processos que têm por fim aplicar as penas de nos 5 e 6 do artigo infra;

3 ? - resolver, ainda mediante recurso, as questões relativas à aposentadoria e às licenças dos funcionários.

\section{CAPITULO VII}

\section{Ação Disciplinar} sầ:

Art. 26. As penas disciplinares

19 - censura particular ou pública, verbal ou escrita;

2: - remoção;

3 ? - multas, que não poderăo exceder a oitava parte dos seus vencimentos;

49 - eliminação do quadro de promoção por um ou dois anos;
5 ? - suspensão do exercício do cargo, com perda parcial dos vencimentos e perda total do tempo, não podendo exceder a seis meses, salvo caso de reincidência;

$$
6 \text { ○ - demissão. }
$$

Parágrafo único. As penas dos números $1,2,3$ e 4 serão aplicadas pelos Ministros ou chefes de serviço, com recurso, nos casos de remoção, eliminação dos quadros, ou multas, para o respectivo Conselho Administrativo; as penas de números 5 e 6 serão aplicadas pelo Conselho Administrativo, com recurso para o Conselho Superior de Disciplina.

Art. 27. As decisões destes Conselhos serão proferidas após um processo regular escrito, onde se garanta ao acusado plena e ampla defesa, inclusive citação de testemunhas e nomeação de advogado.

$\S 19$ Cada Ministro nomeará um seu representante, que exerça as funções do Ministério Público.

$\S 2$ O $O$ recurso pode ser intentado pelo acusado ou pelo representante do Ministério Público. 
